\title{
Adolescência e sexualidade: scripts sexuais a partir das representações sociais
}

\author{
Adolescence and sexuality: sexual scripts from the social representations \\ Adolescencia y sexualidad: scripts sexuales a partir de las representaciones sociales
}

\section{Senei da Rocha Henrique Macedo', Francisco Arnoldo Nunes de Miranda', João Mário Pessoa Júnior', Vannucia Karla de Medeiros Nóbrega'}

'Universidade Federal do Rio Grande do Norte, Departamento de Enfermagem, Programa de Pós Graduação em Enfermagem. Natal-RN, Brasil.

\author{
Submissão: 12-06-2011 Aprovação: 06-02-2013
}

\section{RESUMO}

Objetivou-se apreender as representações sociais de adolescentes sobre sexualidade, a partir de suas experiências pessoais. De natureza qualitativa e representacional, a pesquisa foi desenvolvida junto a treze adolescentes numa unidade de educação de jovens e adultos, tendo como instrumento de coleta de dados a entrevista semiestruturada e o grupo focal. Verificou-se a coexistência de dúvidas quanto à sexualidade e sua relação ao ato sexual propriamente dito; ausência de diálogos entre pais e filhos nessa temática; e abordagem escolar ainda incipiente, com limitações dos conteúdos quanto ao uso de camisinha. As representações sociais nesse estudo se ancoram na sexualidade como ato sexual, e são objetivadas por meio dos scripts social e sexual, que conferem aos adolescentes um saber prático sobre si.

Descritores: Sexualidade; Adolescente; Educação; Enfermagem.

This study aimed to identify the social representations of adolescents about sexuality, from their personal experiences. The research, of a qualitative and representational nature, was carried out with thirteen teenagers in a unit of education for young and adults. It has, as instrument for data collection, a semi-structured interview and focus group meetings. It was observed the coexistence of questions regarding sexuality and its relation to the sexual act itself; absence of dialogue between parents and children about this theme; and incipient school approach, with limitations of the contents about condom use. In this study, the social representations are anchored in sexuality as sexual act, objectified through social and sexual scripts, which gives teens a practical knowledge about themselves.

Key words: Sexuality; Adolescent; Education; Nursing.

\section{RESUMEN}

Este estudio tuvo como objetivo conocer las representaciones sociales de los adolescentes acerca de la sexualidad, a partir de sus experiencias personales. La investigación, de carácter cualitativo y de representación, se llevó a cabo con trece adolescentes, en una unidad de educación para jóvenes y adultos. Tuve, como instrumentos para recolección de datos, una entrevista semiestructurada y reuniones de grupos focales. Se observó la coexistencia de cuestiones relacionadas con la sexualidad y su relación con el acto sexual en sí; ausencia de diálogo entre padres e hijos acerca de este tema; y enfoque incipiente de la escuela, con limitaciones de los contenidos cuánto al uso del condón. En este estudio, las representaciones sociales están ancoradas en la sexualidad como acto sexual, e objetivadas a través de scripts sociales y sexuales, que dan a los adolescentes un conocimiento práctico sobre sí mismos.

Palabras clave: Sexualidad; Adolescente; Educación; Enfermería. 


\section{INTRODUÇÃO}

Preocupações recorrentes quanto à vivência da adolescência e seus desdobramentos no processo de desenvolvimento e crescimento, especialmente aqueles adolescentes em situações de vulnerabilidade expostos a drogas licitas e ilícitas, à gravidez precoce, à prostituição, à violência e à delinqüência infanto-juvenil, associada à tímida presença, dessa faixa etária, nas unidades de saúde tornaram-se inquietações frente à atenção ao atendimento aos adolescentes, particularmente no que diz respeito às manifestações da sexualidade, dentre outras. Assim, questiona-se: a condição de adolescente associada a situações de vulnerabilidade e pouca habilidade de vida refletem nas manifestações de sexualidade do mesmo?

A partir deste questionamento, entende-se que as necessidades sexuais são semelhantes e diferentes de outras necessidades básicas; em termos de sobrevivência de um indivíduo, o sexo não é uma necessidade essencial, assim como o são os líquidos, a nutrição ou o oxigênio ${ }^{(1)}$.

A sexualidade constitui-se numa dimensão fundamental em todo ciclo de vida de homens e mulheres, a qual envolve práticas e desejos ligados à satisfação, à afetividade, ao prazer, aos sentimentos, ao exercício da liberdade e à saúde. Desta forma, é uma construção histórica, cultural e social, e se transforma conforme mudam as relações sociais. Mas, infelizmente, em nossa sociedade ocidental, foi histórica e culturalmente limitada em suas possibilidades de vivência, devido a tabus, mitos, preconceitos, interdições e relações de poder ${ }^{(2)}$.

Nas últimas três décadas, algumas mudanças ocorreram no estilo de vida da população, incluindo seus valores, crenças e tabus, principalmente, aqueles relacionados à sexualidade. Hoje os profissionais de saúde e a sociedade em geral estão deixando de controlar a vida sexual dos jovens, transferindo para eles próprios a responsabilidade por sua conduta sexual ${ }^{(3)}$.

De uma maneira geral, o problema da sexualidade humana diz respeito ao papel da enfermagem uma vez que muitos problemas e tratamentos de saúde afetarão a sexualidade e as capacidades sexuais de um paciente, temporária ou permanentemente, que é afetada por fatores sociais, culturais e religiosos, além da estrutura física, do funcionamento e da aparência ${ }^{(1)}$.

A Organização Pan-americana de Saúde (OPAS) e a Organização Mundial de Saúde (OMS) definem a adolescência como um processo fundamentalmente biológico de vivências orgânicas, no qual se aceleram o desenvolvimento cognitivo e a estruturação da personalidade. Abrange a pré-adolescência que compreende a faixa etária de 10 a 14 anos e a adolescência propriamente dita, dos 15 anos aos 19 anos.

Sobre os serviços de saúde, afirma-se que inúmeros deles

encontram-se despreparados para o trabalho com adolescentes, para a atenção às peculiaridades e complexidades das suas necessidades. Faltam espaços e suporte apropriados às suas demandas, seja no campo da orientação, proteção ou recuperação da sua saúde sexual e reprodutiva. Os sentidos do corpo e as desigualdades e diferenças de distintas ordens são freqüentemente ignoradas, num processo de homogeneização e simplificação da saúde adolescente( ${ }^{(4)}$.
Concorda-se que a Enfermagem tem uma responsabilidade fundamental no trabalho em saúde com adolescentes, tendo em vista: a busca da eqüidade na realização das práticas em saúde/enfermagem; o contínuo questionamento das normatizações sociais hierárquicas e dos valores diferenciais em torno da sexualidade e reprodução; a ampliação da autonomia e corresponsabilização de adolescentes homens e mulheres no lidar com a vida, a sexualidade, a maternidade/paternidade, resgatando-se o seu caráter relacional; e a prevenção de agravos que trazem sofrimentos à vida ${ }^{(5)}$.

Em vista desses aspectos, definiu-se como objetivo geral para este trabalho o de apreender as representações sociais de adolescentes sobre sexualidade, a partir de suas experiências pessoais.

\section{MÉTODOS}

Trata-se de estudo descritivo, com abordagem metodológica qualitativa, fundamentado na Teoria das Representações Sociais ${ }^{(6)}$. A pesquisa foi realizada no município de Jandaíra, no Rio Grande do Norte (RN), especificamente na Unidade de Educação de Jovens e Adultos (EJA). Projetou-se como população do estudo os alunos regularmente matriculados na EJA, da zona urbana, com faixa etária de 15 a 19 anos. Acrescenta-se que a faixa etária dos sujeitos da pesquisa atende, de um lado, às recomendações da OPAS e OMS (10 a 19 anos), e do outro aquela estabelecida pelo EJA (15 a 19 anos), cuja matrícula é deferida a partir dos 15 anos.

A princípio, foram captados dezessete adolescentes desejosos de participar da pesquisa, mas, devido a alguns contratempos, como a dificuldade no relacionamento entre pais e filhos e a ausência destes no ambiente escolar, referido pelos professores, esse número foi reduzido.

Ao invés de uma reunião com os pais no âmbito escolar, optou-se pela busca, de casa em casa, das assinaturas para liberação da participação dos adolescentes na investigação. Acresça-se a estas dificuldades que, além da evasão escolar, característica da EJA, há alunos que a frequentam esporadicamente e/ou aqueles que passam na escola e se dirigem às ruas, sem permanecer em sala de aula. Diante dessa realidade, o número de alunos ficou bem abaixo do esperado, compondo-se a uma amostra com treze sujeitos, sendo seis do sexo masculino e sete do sexo feminino.

Dessa forma, concorda-se que, em particularidades como estas, a definição dos sujeitos se deu pela constituição de um grupo metodologicamente representativo do universo considerado ideal, contrastado pelos fatores intervenientes que determinam o tamanho do mesmo. Portanto, a delimitação do número decorre da caracterização consistente desse universo e de como se articula o objeto teoricamente ${ }^{(7)}$.

Para efeito desse estudo, utilizou-se como técnica de coleta de dados, no primeiro momento, a entrevista semiestruturada, guiada por um conjunto de questões sobre a sexualidade e sua relação com o ato sexual propriamente dito; diálogos entre pais e filhos sobre essa temática; qual a abordagem na escola sobre sexualidade e quanto ao uso de métodos contraceptivos; entre outros. No segundo momento, realizou-se um grupo focal. Dentre as várias proposições para trabalhar com grupos de 
adolescentes, optou-se por aquela que significa uma ruptura com o transcurso natural da adolescência, a gravidez precoce.

Entende-se que o adolescente, ao situar-se nesse campo transicional participa ativamente do processo, emitindo conteúdos discursivos e/ou não verbais sobre o que sabe e não sabe a respeito da sua própria sexualidade. Dessa forma, adquire importante significado na apreensão das representações sociais, pois é um meio de expressão e comunicação na área intermediária entre realidade interna e externa, e ainda, possibilita o relacionar-se com a vivência do mesmo e o drama que nele se desenvolve ${ }^{(8-10)}$.

Assim, trabalhamos com a dramatização de uma história o Estudo de Caso da História de Camila ${ }^{(5)}$. Nele é abordado o início de um namoro que culminou em uma possível relação sexual. Para realização do primeiro ato, foram convidados três adolescentes voluntários para interpretação dos personagens da história de Camila. No segundo ato, todos os integrantes do grupo focal participaram da discussão.

Menciona-se que a substância operante da representação social na construção da realidade é o significado que ela dá ao objeto ${ }^{(11)}$. Alcançar a representação social é, pois, em si, um exercício de interpretação: a pesquisa visa exatamente a coleta de indícios e a sua sistematização pelo(a) pesquisador(a), a partir dos referenciais do próprio grupo e de vários recursos. Portanto, a coleção de dados que se obtém e se processa, ainda não é a representação social - ela surge da costura que só o olhar do pesquisador(a) pode fazer, numa perspectiva holística e integradora, uma vez que a representação social é uma forma de expressão criativa dos sujeitos, situada na interface do psicológico e do social ${ }^{(11)}$.

Optou-se pela análise de edição onde o pesquisador age como intérprete, que lê os dados em busca de segmentos significativos. Desta forma, os segmentos são identificados e revistos, desenvolvendo-se um esquema de classificação e códigos correspondentes, podendo ser usados para distribuir e organizar os dados. Por fim procuram-se os padrões e as estruturas que conectam as categorias temáticas ${ }^{(12)}$.

A busca das representações sociais a partir da análise de edição justifica-se pelo fato de que ambas remetem à compreensão de aspectos pouco aclarados do objeto de pesquisa, quer conceituais, quer práticos, que permeiam a cotidianidade dos sujeitos psicossociais, na revitalização do conhecimento produzido na interface da reificação da ciência e do senso comum. Neste sentido, os processos sociocognitivos e as dimensões constituintes das representações sociais dão esta clarificação do objeto, pois oferecem, como ponto de partida para a problematização, a pluralidade dos significados e imagens construídas sobre o objeto em apreensão, particularmente, a sexualidade na adolescência e suas habilidades de vida.

Ressalta-se que a pesquisa foi aprovada pelo Comitê de Ética em Pesquisa da Universidade Federal do Rio Grande do Norte (CEP/UFRN) sob o protocolo de número 089/08, CAAE 101.0.051.000.08.

\section{RESULTADOS E DISCUSSÃO}

A utilização da Técnica de análise de edição na perspectiva teórica das representações sociais possibilitou a identificação, frente aos dados levantados junto aos sujeitos da pesquisa, de três dimensões: Dimensão 01 - O saber comum sobre a sexualidade; dimensão 02 - O saber compartilhado sobre a sexualidade; Dimensão 03 - Tomada de posição frente à sexualidade. Ressalta-se de antemão, que não está em questão separar temas em compartimentos estanques, mas captar as formas pelas quais se dá esta abordagem e as transformações que opera.

\section{Dimensão 01 - O saber comum sobre a sexualidade}

O saber comum sobre a sexualidade diz respeito à informação, ou seja, "a organização dos conhecimentos que um grupo possui a respeito de um objeto social"(7). O conceito de sexualidade para os adolescentes do estudo diz respeito às manifestações diretamente ao ato sexual, evidenciado nessas falas:

Sexualidade acho que é assim a pessoa fazer sexo (Demeter)

Eu acho assim se o cara faz sexualidade e acontecer alguma coisa, ele tem que assumir (Adonis)

Acho que é ter relação sexual um rapaz e uma moça tem um com o outro, é isso? (Hera)

As representações sobre sexualidade limitaram-se a relação sexual entre duas pessoas do sexo oposto ${ }^{(13)}$. A questão da sexualidade está direcionada aos atos sexuais ou ao relacionamento a dois ${ }^{(14)}$. E, ainda os adolescentes mostraram-se bastantes confusos quanto à concepção da sexualidade, compreendem-na a partir dos aspectos relativos ao prazer e à reprodução, com uma limitação da visão multidimensional dos fatores que a envolvem.

Dimensão 02 - O saber compartilhado sobre a sexualidade

Quanto ao saber compartilhado sobre sexualidade esse se reporta ao campo representacional, o qual "remete à idéia de imagem, de modelo social, ao conteúdo concreto e limitado das proposições acerca de um aspecto preciso do objeto da representação" ${ }^{\prime(7)}$.

No contexto do adolescer, verificou-se no transcurso das conversas sobre sexualidade que as informações compartilhadas geralmente ocorrem entre os pares (amigos, sexo oposto e namorados), na família e na escola. Apresenta-se a seguir subcategorias desses diálogos inter-grupais imbricados nos contextos pertencentes aos adolescentes, família e escola.

\section{Diálogo sobre sexualidade no contexto do grupo de per- tencimento dos adolescentes}

Sabe-se que na adolescência ocorre a busca de identidade e geralmente os adolescentes procuram as pessoas fora da família para servir como referência na formação de personalidade e conseqüentemente atitudes. Desta forma a influência dos pares adquiriu caráter fundamental na vivência no processo de adolescer.

Num estudo(7) sobre a psicanálise observou-se que dentre os sujeitos pesquisados, a posição assumida pelos adolescentes (estudantes e alunos de escolas técnicas) encerra uma equação simbólica entre a idade em que se formulam os 
problemas da autonomia individual e a ajuda que a psicanálise propõe, cujas respostas dos sujeitos revelaram uma atitude favorável. Dessa constatação, contrariamente observou que os adultos não querem tomar posição ou não tem idéias claras sobre a temática. Portanto, o indivíduo é observado e compreendido através de traços próprios da tipologia dominante, exercendo-se por vezes uma pressão coletiva para fazer coincidir o comportamento real com as categorias geralmente admitidas $^{(7)}$.

Nesse contexto, observou-se, conforme falas abaixo transcritas, um compartilhar maior de vivencias e experiências entre a temática e a categoria em que se está inserido, uma vez que dos 13 participantes da pesquisa, 05 referiram conversar ou trocar informações sobre sexualidade com outros adolescentes do mesmo sexo, 03 com o namorado, 03 com adolescentes do sexo oposto e 02 com familiares:

\section{Converso com minhas amigas (Hebe)}

\section{Converso com amigos (Hermes)}

Com minha namorada quando agente fica só, só ficar mesmo (Helio)

\section{Converso só com as meninas (Adonis)}

\section{Com minha irmã de 26 anos (Atena)}

Dessa forma, os resultados desse estudo corrobora com as idéias dos autores ${ }^{(13)}$, onde os amigos foram apontados pela maioria dos adolescentes como o grupo em que se sentem mais à vontade para conversar sobre sexualidade.

\section{Diálogo sobre sexualidade no contexto da família}

Esse contexto foi fortemente marcado pela ausência de diálogo familiar sobre sexualidade, onze adolescentes referiram não conversar com os pais sobre sexualidade, seguem abaixo algumas falas:

Converso com ela não, eu tenho vergonha de fala sobre isso (Hermes)

Minha mãe ainda não conversou sobre isso não (Hércules)

Na fala de Hermes, o fator vergonha é o grande inibidor do diálogo com a família, inferindo-nos a pensar sobre o relacionamento entre pais e filhos e as restrições existentes sobre alguns assuntos, como, por exemplo, a própria sexualidade. Nessa perspectiva um estudo ${ }^{(15)}$ aponta que o diálogo entre pais e filhos adolescentes é restrito, podendo estar associada à possibilidade das atitudes repressoras dos pais. Tendo em vista que tabus e preconceitos impedem o indivíduo, de até mesmo, buscar aprender.

Dessa forma a dificuldade em procurar os pais para esclarecer dúvidas sobre assuntos relacionados à sexualidade pode está pautado na proibição do sexo, ausência de diálogo, tons de ameaça, impedindo a fluidez da conversa em família.
Neste sentido os pais embasados pela crença que a conversa sobre sexo serve como indução ao inicio da atividade sexual, protelam o diálogo sobre sexualidade ${ }^{(14-15)}$.

A fala de Hércules chama-nos atenção por remeter-se a idéia de espera, uma vez que enfatiza o termo "ainda", aguardando que a iniciativa de conversar sobre sexualidade em algum momento de sua vida parta dela, sua mãe.

Apenas duas participantes relataram conversas sobre sexualidade com a mãe, cujo conteúdo dos diálogos reporta-se, especificamente, à condição reprodutiva, guiados pelos cuidados ao evitar gravidez, nas condições de solteira e casada. Tal posição, conforme as falas abaixo, leva a seguinte indicação, métodos contraceptivos e camisinha para solteiras, anticoncepcional para as casadas:

[...] como todas as mães diz ... a mulher é fazer de tudo para não pegar um bucho, porque se pegar fora de casa... Ela já falou para mim assim... casal casado e aqueles ficantes... Comprimido só presta quando é casado mesmo, que tem relações todos os dias, mas a camisinha já ...é para quem não tem relações todos os dias (Hestia)

\section{Diálogo sobre sexualidade no contexto da escola}

A importância de trazer a discussão da sexualidade para o universo escolar perpassa a idéia de experiência que se desenha exclusivamente no espaço privado ou individual do adolescente, quando na verdade, revela uma trajetória social. Dessa forma, considera-se a escola por um lado, como local de interações e relações socioeconômicas e culturais e, por outro, espaço para promoção da saúde, com enfoque de ações educativas, de construção da cidadania envolvendo os sujeitos que a compõem: adolescentes, estudantes, professores, funcionários, familiares e profissionais de saúde ${ }^{(5)}$.

No que se refere a educação sexual no ambiente escolar, reconhece-se a importância de articular a sexualidade com a promoção da saúde, pois viabiliza a realização de ações preventivas das Doenças Sexualmente Transmissíveis e AIDS, de reflexão sobre a violência sexual e a gravidez precoce, bem como a discussão sobre a própria sexualidade, ampliando a percepção do adolescente sobre o auto cuidado e o auto conhecimento $^{(16)}$.

No entanto, essas discussões no contexto escolar, apresentam-se escassas como observa-se nas falas a seguir:

Conversam algumas vezes... Assim, eles falam o que precisa usar quando faz sexo... Na matéria de Ciência..." (Hebe)

Conversam. Eles falam que caso agente quiser fazer é para usar camisinha para evitar doenças nesse meio de mundo ai... ensinando assim as doenças, uma vez eles mostraram umas feias que só... ai distribuíram camisinhas (Hera)

Sobre sexualidade teve uma de religião sobre opção do sexo, sobre gays (Demeter)

[...] Só teve uma aula ... agente ta estudando sobre ficar... Ela utilizou um trabalho...o que é ficar para você? (Hestia) 
Destaca-se que os conteúdos sobre sexualidade foram abordados de maneira superficial, gerando lacunas na construção de conhecimentos, limitados enfaticamente na importância do uso da camisinha na prevenção de doenças.

Ao indagarmos sobre dúvidas na temática sexualidade, destacou-se uma diferença entre os sexos masculino e feminino: os meninos, 50\% referiram ter dúvidas e a outra metade não admitiu tê-las, já entre as meninas $71 \%$ referiram ter dúvidas sobre sexualidade. Somente as adolescentes do sexo feminino compartilharam-nas durante a entrevista:

O que é sexualidade? Eu não sei realmente o significado de sexualidade (Atena)

Quando perde a virgindade o que acontece? Geralmente quando perde a honra, tenho medo assim se pega filho, assim num instante... Só essas duas que vive atormentando meu pensamento, fico assim pensando...porque geralmente as meninas de hoje tem medo de perder e se pega menino, embora tenha muitas que pegam porque quer (Afrodite)

Essas falam demonstram a falta de conhecimento do adolescente sobre a própria sexualidade, e o que de fato a envolve, demonstrando seu enfrentamento em meio as experiências vividas e dúvidas. Isto nos remete a forma como é feita a abordagem da sexualidade no âmbito escolar, que ainda acontece de forma incipiente uma vez que é notória a ocorrência de dúvidas, mitos, e ideias preestabelecidas ${ }^{(17)}$.

\section{Dimensão 03: tomada de posição frente à sexualidade}

A tomada de posição frente à sexualidade, configura-se como a atitude que "termina por focalizar a orientação global em relação ao objeto da representação social"(7). Entende-se que no contexto do adolescer muitas serão as decisões tomadas, dessa forma, procurou-se apreender as atitudes desses adolescentes, a partir de sua compreensão, especialmente quanto ao uso de contraceptivos e o uso da camisinha na prevenção de DSTs e AIDS. Segue abaixo a seguintes subcategorias: sexualidade e contraceptivos; DSTs e AIDS; sexualidade e autocuidado.

\section{Sexualidade e métodos contraceptivos}

No que concerne a sexualidade, contracepção e adolescência muitas são as discussões sociais que permeiam essa vivência, haja vista as muitas implicações advindas desta fase da vida. A exemplificar a não permissão social para o inicio das relações sexuais e a ocorrência natural dessas.

"A sexualidade não se circunscreve às situações românticas ou amorosas. A conjugação amor/sexo não é uma necessidade biológica, nem um imperativo social, mas, apenas, uma das possíveis soluções histórico-culturais para o problema da articulação entre reprodução biológica e vinculação social"(20).

Neste sentido a escolha, bem como a forma do uso dos métodos contraceptivos, também é socialmente construída, visto que seu uso está atrelado a diversas formas de como o individuo tem acesso à informação e ao próprio método, como a sociedade aceita o seu uso, os tabus advindos das práticas por outros vivenciados.

Sei, tem que usar sempre camisinha e a mulher tem que tomar remédio para evitar (Hércules).

Para evitar doenças... homem você já sabe. Fica com uma, fica com outra, e aí preferia a camisinha para evitar alguma coisa. Porque eu tenho medo, as coisas de hoje em dia, as doenças feias do mundo, Deus me livre, eu vejo os comentários da mulher na televisão dizendo aqueles negócios. Dizendo que, se tivesse usado camisinha, não tinha sido contaminada com as doenças, se elas tivesse usado (Hera)

Concorda-se que os adolescentes requerem um suporte de vários setores sociais através de políticas, recursos e processos de trabalho intersetoriais, interdisciplinares e participativos, em que se disponibilize uma atenção integral, específica às suas necessidades com ações desenvolvidas em diferentes espaços $^{(4)}$. Visto que estão vislumbrando a possibilidade de reprodução e experiências novas no âmbito da sexualidade.

Doenças sexualmente transmissíveis e o uso da camisinha

Sobre o conhecimento das doenças sexualmente transmissíveis, apenas dois adolescentes não souberam responder, destacando-se como a mais citada, a AIDS e a gonorreia. Constatou-se mediante as falas dos adolescentes que a associação da AIDS esteja atrelada aos mecanismos midiáticos de divulgação do uso do preservativo por ocasião de grandes festas populares e pela ação das campanhas ministeriais. Enquanto a gonorréia pode ser um fato mais freqüente na realidade local.

\section{Apreendi sozinho, vendo DVD (Helio)}

Eu assisto TV... em programas educativos quando passa eu assisto (Hermes)

\section{Sexualidade e autocuidado}

As meninas reconhecem a necessidade de realizar exame ginecológico, mas se privam de fazê-lo por medo e/ou vergonha de realizá-lo. Tal conduta contribui para a condição de vulnerabilidade das adolescentes frente às limitações psicológicas advindas dos valores e tabus da sociedade, circunscritos na esfera do senso comum.

[...] eu tava com essa dor no útero e quando fez, ficou dando uma dorzinha, fiquei meia balanceada, achando que foi alguma doença (Afrodite)

Em uma relação heterossexual não é a mulher que "veste a camisinha", mas sim o homem ${ }^{(20)}$. E se essa iniciativa partir da mulher, principalmente no modelo monogâmico, esta terá que pedir consentimento ao parceiro que de modo geral, é contrário ao uso (além de pôr em questão a monogamia e confiança da relação) ${ }^{(20)}$. 


\section{Representação Social, Sexualidade e Adolescência}

Afirma-se que a psicanálise na sociedade está ligada a toda série de fenômenos da sexualidade, suscitando uma conscientização do seu caráter 'tabu' e de suas repercussões sobre a personalidade; ela está associada, portanto, em seu conjunto, ao comportamento sexual do indivíduo(5). Dessa forma, após o aparecimento da psicanálise acentuaram-se as interdições concernentes a vida sexual.

Para alguns estudiosos ${ }^{(5,19)}$, a objetivação e ancoragem são processos sociocognitivos, intrinsecamente ligados e não são seqüenciais, embora freqüentemente destacado em separado para simples compreensão didática.

Neste estudo, destaca-se como os adolescentes articulam os conteúdos e as informações que dão compreensão à sexualidade. Ancoram a sexualidade como o ato sexual em si, entre pessoas do sexo oposto. Descartando qualquer outro tipo de comportamento referente as manifestações diversas de sexualidade, inferindo-se um ocultamento ou silenciamento sobre a homossexualidade. Em ambas as perspectivas, ancoram posições contrárias na dimensão do que é dito e do não dito decorrentes de traços culturais, revelando a funcionalidade desse processo, permitindo compreender a forma como os adolescentes expressam e constituem suas relações sociais através da comunicação verbal e não verbal ${ }^{(5)}$.

A objetivação apreendida sobre a sexualidade, a partir da experiência e compreensão dos adolescentes sobre a temática, assenta-se no modo como a sociedade estabelece as informações e o posicionamento dos sujeitos biopsicossociais, independente de sexo, idade, etnia ou classe social. Entendido como papéis sociais e sexuais a sempre desempenhados, quer no espaço público, quer privado sobre quais condições e situações são permitidas falar e manifestar a sexualidade. Nesse sentido, optamos pelo constructo do script social e sexual.

O conceito de script é essencialmente uma metáfora para conceptualizar a produção de comportamentos no interior da vida social, enquanto os scripts sexuais são esquemas (socialmente construídos) de atribuição de significação de orientação (direção) da ação. Esses scripts sexuais constituem um caso particular dos scripts sociais ${ }^{(19)}$.

Do ponto de vista das suas funções o conceito de scripts aproxima-se do conceito de representação social(6). Observando as semelhanças com as representações sociais, os scripts referem-se a modalidades de conhecimento prático, socialmente elaboradas e partilhadas, constituindo, simultaneamente sistemas de interpretação e de categorização do real e modelos ou guias de ação.
Neste sentido as representações sociais dos adolescentes sobre sua sexualidade e como a vivencia, pode ser apreendida através do esquema figurativo, uma vez que se apóiam sobre um pensamento social imbricado no nível mais profundo e determinante da realidade, porque ambos os enfoques são complementares na perspectiva dos processos sociocognitivos. Ou seja, ancoram a sexualidade como ato sexual, objetivado através dos scripts social e sexual, que confere aos adolescentes um saber prático sobre si e as manifestações da sexualidade.

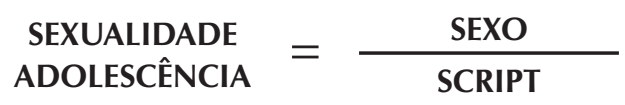

Figura 1 - Esquema figurativo das representações sociais dos adolescentes sobre sua sexualidade, a partir de suas experiências.

\section{CONSIDERAÇÕES FINAIS}

Destaca-se que estudar representações sociais no grupo investigado se, de um lado existe uma dificuldade na sua apreensão pela limitação do conhecimento teórico do assunto, do outro o pensamento ingênuo sobre o mesmo se coloca como uma possibilidade capaz de sua apreensão, pois é no manejo da vida cotidiana que os sujeitos biopsicossociais dão sentido e orientação aos objetos de compartilhamento social.

Assim, a maneira como o individuo vivencia sua sexualidade está norteada pelo sexo feminino ou masculino, fator este gerador de atitudes, estabelecendo um domínio público da sua opção e escolha sexual, quando solteira, quando casada. Corresponde, dessa maneira, ao script social e sexual de sua condição.

A compreensão dessa estrutura foi facilitada pela adoção da teoria das representações sociais, que ajuda a compreender o que as pessoas pensam, porque pensam e quais os desdobramentos deste pensar sobre um determinado assunto, particularmente aqueles considerados tabus.

Esta visão foi constatada nas três principais dimensões da pesquisa: dimensão 1 - o saber comum sobre a sexualidade; dimensão 2 - O saber compartilhado sobre a sexualidade; dimensão 3 - tomada de posição frente a sexualidade. As dimensões identificadas remetem a regras e práticas; à condição de quando falar, usar métodos contraceptivos e obter informações sobre a sua sexualidade; bem como, ao sentido e à orientação que atribuem ao ato sexual na esfera do pertencimento social.

\section{REFERÊNCIAS}

1. Atkinson LD, Murray ME. Fundamentos de Enfermagem: introdução ao processo de enfermagem. Rio de Janeiro: Guanabara-Koogan; 1989.

2. Ministério da Saúde. Departamento de Ações Programáticas Estratégicas. Marco teórico e referencial: saúde sexual e saúde reprodutiva de adolescentes e jovens. Brasília,
DF: O Ministério; 2006.

3. Dias A, Bueno SM. Programa educativo sobre sexualidade, DST/Aids e sexo seguro, desenvolvimento junto ao aluno do curso técnico de enfermagem: um relato de experiência. Rev Nurs 2003;90(6):14-21.

4. Mandú ENT. Adolescência: Saúde, sexualidade e 
reprodução. In: Associação Brasileira de Enfermagem. Projeto Acolher: Adolescer, compreender, atuar, acolher. Brasília: ABEn; 2001. p.304.

5. Associação Brasileira de Enfermagem. Adolescer: compreender, atuar, acolher: Projeto Acolher. Brasília, DF: ABEn; 2001.

6. Moscovici S. Answers and questions. Journal for the Theory of Social Behaviour 1987;17(4):513-529.

7. Madeira MC. Representações sociais e processo discursivo. In: Moreira ASP, Camargo BV, Jesuíno JC, Nóbrega SM (organizadoras). Perspectivas teórica-metodológicas em representações sociais. João Pessoa: Editora Universitária da UFPB; 2005.

8. Winnicott DW. O brincar e a realidade. Rio de Janeiro: Imago; 1975.

9. Miranda FAN, Furegato ARF. Instrumento projetivo para estudos de representações sociais na saúde mental. SMAD, Rev Eletrônica Saúde Mental Álcool Drog 2006;2(1)1-14.

10. Vaisberg TMJA. O uso de procedimentos projetivos na pesquisa de representações sociais: projeção e transicionalidade. Rev Psicol USP 1995;6(2):103-27.

11. Arruda A. Despertando do pesadelo: a interpretação. In: Moreira ASP, Camargo BV, Jesuíno JC, Nóbrega SM (organizadores). Perspectivas teórico-metodológicas em representações sociais. João Pessoa: Editora Universitária da UFPB; 2005.

12. Polit DF, Beck CT, Hungler BP. Fundamentos de Pesquisa em Enfermagem: Métodos, avaliação e utilização. 5. ed. Porto Alegre: Artes Médicas; 2004.

13. Nery IS, Mendonça RCM, Gomes IS, Fernandes ACN,
Oliveira DC de. Reincidência de gravidez em adolescentes de Teresina, PI, Brasil. Rev Bras Enferm 2011;64(1):31-7.

14. Beserra EP, Pinheiro PNC, Barroso MGT. Ação Educativa do Enfermeiro na Prevenção de Doenças Sexualmente Transmissíveis: Uma investigação a partir das adolescentes. Esc Anna Nery Rev Enferm 2008;12(03):522-528.

15. Sousa LB, Fernandes JFP, Barroso MGT. Sexualidade na adolescência: análise da influência de fatores culturais presentes no contexto familiar. Acta Paul Enferm 2006;19(4):408-13.

16. Pereira KC. Sexualidade na adolescência: trabalhando a pesquisa-ação com referenciais teórico-metodológicos de Paulo Freire. Dissertação [Mestrado em Enfermagem] -Escola de Enfermagem de Ribeirão Preto-Universidade de São Paulo; 2007.

17. Barreto TA, Ribeiro CV, Oliveira MAS. Educação e saúde: problematizando gênero e sexualidade em uma escola municipal de Juazeiro-BA. Res Educ Vale São Francisc 2010;1(1):33-47.

18. Alferes VR. Atração Interpessoal, Sexualidade e Relações Intimas. In: Vala J, Monteiro MB. Psicologia Social. 6. ed. Lisboa: Fundação Calouste Gulbenkian; 2004.p. 625.

19. Vala J. Representações Sociais e Psicologia Social do Conhecimento. In: Vala J, Monteiro MB. Psicologia Social. 6. ed. Lisboa: Fundação Calouste Gulbenkian; 2004. p.457-502.

20. Torres GV, Miranda FAN, Meneses RMV, Simpson CA, Carvalho IHS. Conteúdos simbólicos, crenças e representações sociais para um grupo de portadores de HIV. In: I Colóquio Luso-Brasileiro sobre Saúde, Educação e Representações Sociais. Évora/Portugal: Universidade de Évora (PO); 2008. 